\title{
The complex impact of silicon and oxygen on the n-type conductivity of high-Al-content AlGaN
}

Anelia Kakanakova-Georgieva, Daniel Nilsson, Xuan Thang Trinh, Urban Forsberg, Son Tien Nguyen and Erik Janzén

\section{Linköping University Post Print}

\section{Tweet}

N.B.: When citing this work, cite the original article.

Original Publication:

Anelia Kakanakova-Georgieva, Daniel Nilsson, Xuan Thang Trinh, Urban Forsberg, Son Tien Nguyen and Erik Janzén, The complex impact of silicon and oxygen on the n-type conductivity of high-Al-content AlGaN, 2013, Applied Physics Letters, (102), 13, 132113. http://dx.doi.org/10.1063/1.4800978

Copyright (2013) American Institute of Physics. This article may be downloaded for personal use only. Any other use requires prior permission of the author and the American Institute of Physics. 


\title{
The complex impact of silicon and oxygen on the n-type conductivity of high-Al-content AIGaN
}

\author{
A. Kakanakova-Georgieva, ${ }^{a}$ D. Nilsson, X. T. Trinh, U. Forsberg, N. T. Son, and E. Janzén \\ Department of Physics, Chemistry and Biology (IFM), Linköping University, SE 58183 Linköping, Sweden
}

(Received 26 February 2013; accepted 25 March 2013; published online 5 April 2013)

\begin{abstract}
Issues of major relevance to the n-type conductivity of $\mathrm{Al}_{0.77} \mathrm{Ga}_{0.23} \mathrm{~N}$ associated with $\mathrm{Si}$ and $\mathrm{O}$ incorporation, their shallow donor or deep donor level behavior, and carrier compensation are elucidated by allying (i) study of $\mathrm{Si}$ and $\mathrm{O}$ incorporation kinetics at high process temperature and low growth rate, and (ii) electron paramagnetic resonance measurements. The $\mathrm{Al}_{0.77} \mathrm{Ga}_{0.23} \mathrm{~N}$ composition correlates to that $\mathrm{Al}$ content for which a drastic reduction of the conductivity of $\mathrm{Al}_{\mathrm{x}} \mathrm{Ga}_{1-\mathrm{x}} \mathrm{N}$ is commonly reported. We note the incorporation of carbon, the role of which for the transport properties of $\mathrm{Al}_{\mathrm{x}} \mathrm{Ga}_{1-\mathrm{x}} \mathrm{N}$ has not been widely discussed. (C) 2013 American Institute of Physics. [http://dx.doi.org/10.1063/1.4800978]
\end{abstract}

Prospective deep-UV light emitting devices stemming from technologies based on AlN invariably integrate n-type high-Al-content $\mathrm{Al}_{\mathrm{x}} \mathrm{Ga}_{1-\mathrm{x}} \mathrm{N}$ layers, $\mathrm{x}>0.70$. The $\mathrm{n}$-type conductivity is conveniently accomplished by doping with $\mathrm{Si}$ introduced into the gas stream mostly as silane $\left(\mathrm{SiH}_{4}\right)^{1-4}$ and occasionally as disilane $\left(\mathrm{Si}_{2} \mathrm{H}_{6}\right){ }^{5}$ Doping of the well-explored $\mathrm{Al}_{\mathrm{x}} \mathrm{Ga}_{1-\mathrm{x}} \mathrm{As}$ alloys, $0<\mathrm{x}<1$, by $\mathrm{Si}_{2} \mathrm{H}_{6}$ has proven potent in many aspects especially when considering their typical growth temperature range of $500-900{ }^{\circ} \mathrm{C}$. ${ }^{6}$ Thermodynamic and kinetic aspects of the $\mathrm{Si}$ incorporation in the $\mathrm{Al}_{\mathrm{x}} \mathrm{Ga}_{1-\mathrm{x}} \mathrm{As}$ alloys by implementing either $\mathrm{SiH}_{4}$ or $\mathrm{Si}_{2} \mathrm{H}_{6}$ dopant gases have been subjected to close investigation. It has being central to the establishment of their controllable n-type doping. Such scrutiny in the case of the high-Al-content $\mathrm{Al}_{\mathrm{x}} \mathrm{Ga}_{1-\mathrm{x}} \mathrm{N}$ alloys is largely prevented by the material growth issues of accomplishing epitaxial layers of high-crystalline quality and surface morphology.

The issue of incorporation of residual impurities, most notably oxygen, has been equally crucial in advancing the understanding and performance of the high-Al-content $\mathrm{Al}_{\mathrm{x}} \mathrm{Ga}_{1-\mathrm{x}} \mathrm{N}$, as well as any $\mathrm{Al}$-containing alloy in general. Ready reaction between the trimethylaluminum (TMAl) precursor and oxygen in the gas stream results in the formation of volatile $\mathrm{Al}\left(\mathrm{CH}_{3}\right)_{2} \mathrm{CH}_{3} \mathrm{OH}$ product, being potentially responsible for the incorporation of oxygen. ${ }^{7}$ The issue of residual oxygen incorporation in the Al-containing alloys is further aggravated by the fact that the maximum $\mathrm{H}_{2} \mathrm{O} / \mathrm{H}_{2}$ ratio allowed-for example, over $\mathrm{Al}_{\mathrm{x}} \mathrm{Ga}_{1-\mathrm{x}} \mathrm{As}$ surface-before oxygen incorporation occurs, is only in the order of $0.01 \mathrm{ppb}^{7}$

Once incorporated into the crystal lattice, the substitutional oxygen $\left(\mathrm{O}_{N}\right)$ is a shallow donor in GaN. $\mathrm{O}_{N}$ in $\mathrm{AlN}$ is commonly associated with deep levels, which affect the position of the Fermi level and counteract the electrical activity of any other donors. ${ }^{8,9}$ Alternatively, it has been suggested that oxygen incorporation does not have a negative effect in achieving n-type $\mathrm{Al}_{\mathrm{x}} \mathrm{Ga}_{1-\mathrm{x}} \mathrm{N}(\mathrm{x} \sim 0.60)$, but rather enhances the conductivity. ${ }^{2}$ The speculated $\mathrm{Si}$ transition from shallow donor in GaN to a localized deep $\mathrm{DX}$ center in $\mathrm{Al}_{\mathrm{x}} \mathrm{Ga}_{1-\mathrm{x}} \mathrm{N}$ alloys with increasing $\mathrm{Al}$ content is under a continuing

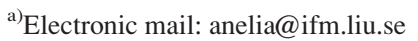

debate following first-principle calculations of substitutional silicon $\left(\mathrm{Si}_{\mathrm{Al}}\right)$ in AlN. ${ }^{8,9}$

Issues of major relevance to the n-type conductivity of high-Al-content $\mathrm{Al}_{\mathrm{x}} \mathrm{Ga}_{1-\mathrm{x}} \mathrm{N}$ alloys associated with $\mathrm{Si}$ and $\mathrm{O}$ incorporation, their shallow donor or deep donor level (DX) behavior, and carrier compensation sustain a subject of controversy and a better understanding is yet to emerge. The present study aims at incorporation kinetics study of $\mathrm{Si}$ and $\mathrm{O}$ in high-Al-content $\mathrm{Al}_{0.77} \mathrm{Ga}_{0.23} \mathrm{~N}$ layers, especially with $\mathrm{Si}$ doping that can produce efficient carrier concentration. The incorporation kinetics study is allied with electron paramagnetic resonance (EPR) measurements, which are essential to distinguish any DX nature of involved point defects. ${ }^{10,11}$ The alloy composition of the studied layers correlates to that $\mathrm{Al}$ content for which a drastic reduction of the n-type conductivity of $\mathrm{Al}_{\mathrm{x}} \mathrm{Ga}_{1-\mathrm{x}} \mathrm{N}$ is commonly reported. The growth kinetics study points to the incorporation of other major impurities in the layers, namely carbon. Its role for the transport properties of high-Al-content $\mathrm{Al}_{\mathrm{x}} \mathrm{Ga}_{1-\mathrm{x}} \mathrm{N}$ alloys has not been widely discussed.

The epitaxial growth is performed in a horizontal-tube reactor based on the Aixtron AB VP508GFR deposition platform and on on-axis semi-insulating $4 \mathrm{H}-\mathrm{SiC}$ substrates. Different aspects of the development of a highly efficient AlN-based epitaxial process, ${ }^{12,13}$ and typical performance of the system as to the AlN growth ${ }^{14}$ and the $\mathrm{Mg}$-doped $\mathrm{Al}_{0.85} \mathrm{Ga}_{0.25} \mathrm{~N}$ layers with low resistivity at room temperature $^{15}$ can be found elsewhere. Following an in-situ template growth, the top $\mathrm{Al}_{\mathrm{x}} \mathrm{Ga}_{1-\mathrm{x}} \mathrm{N}$ :Si layer is grown at a typical process temperature of $1100{ }^{\circ} \mathrm{C}$. Ammonia $\left(\mathrm{NH}_{3}\right), \mathrm{TMAl}$, and trimethylgallium (TMGa) are the precursors introduced with a gas-flow-rate ratio of $\mathrm{NH}_{3} /(\mathrm{TMAl}+\mathrm{TMGa})$ of either 1560 or 640 , at the same $\mathrm{NH}_{3}$ gas-flow-rate. The typical growth rate over $2 \mathrm{in}$. diameter deposition area is maintained at either $\sim 360 \mathrm{~nm} / \mathrm{h}$ or $760 \mathrm{~nm} / \mathrm{h}$, respectively. The typical thickness of the top $\mathrm{Al}_{\mathrm{x}} \mathrm{Ga}_{1-\mathrm{x}} \mathrm{N}$ :Si layer is of $\sim 360 \mathrm{~nm}$. The precursor used for doping is $\mathrm{SiH}_{4}$ at a gas-flow-rate ratio of $\mathrm{SiH}_{4} /(\mathrm{TMAl}+\mathrm{TMGa})$ in the range of $0.2-6.0 \times 10^{-3}$, which determines the nominal doping level. Secondary ion mass spectrometry (SIMS) is employed to obtain the thickness and alloy composition of the $\mathrm{Al}_{\mathrm{x}} \mathrm{Ga}_{1-\mathrm{x}} \mathrm{N}: \mathrm{Si}$ layers, and to 
determine the $\mathrm{H}, \mathrm{C}, \mathrm{O}$, and $\mathrm{Si}$ atomic concentrations. ${ }^{16}$ Cathodoluminescence (CL) panchromatic images from the layers are obtained in a field-emission gun scanning electron microscope with CL attachment (Leo1550 MonoCL2 system, Oxford Res. Instr.) at $5 \mathrm{~K}$ and $10 \mathrm{kV}$. The surface topography of the layers is obtained by atomic force microscopy (AFM) in a tapping mode (Veeco Dimension 3100 Scanning Probe Microscope). The mobility, carrier concentration, and conductivity are measured by contactless microwave-based technique (LEI 1610 Mobility Measurement System, Lehighton Electronics, Inc.). More details of this type of technique can be found elsewhere. ${ }^{17}$ EPR measurements are performed on an X-band $(\sim 9.4 \mathrm{GHz})$ Bruker E500 EPR spectrometer equipped with a continuous He flow cryostat, allowing the regulation of the sample temperature in the range of 4-295 K. For photo-excitation EPR experiments, a $200 \mathrm{~W}$ halogen lamp is used as an excitation source. Illumination with light of different photon energies can be realized using a single grating Jobin-Yvone monochromator and appropriate optical filters.

Given the tightness of the gas system and overall reactor assembly, the concentration of the incorporated oxygen is established to be further reduced by a factor of three by increasing the process temperature from $1000^{\circ} \mathrm{C}$ up to $1100^{\circ} \mathrm{C}$. Such a low value of the residual concentration level of oxygen as $[\mathrm{O}] \sim 3 \times 10^{17} \mathrm{~cm}^{-3}$ in layers of $\mathrm{Al}_{0.77} \mathrm{Ga}_{0.23} \mathrm{~N}: \mathrm{Si}$ composition is attained. The positive impact of increasing the temperature on the reduced oxygen incorporation in AIN has been speculated in the context of increasing the mobility of impurity elements and their drive off from the growth zone possibly after forming molecules with any co-species. ${ }^{18}$ Nevertheless, we emphasize that the high process temperature- $1100^{\circ} \mathrm{C}$ in this case-benefits the development of a smooth surface topography via enhanced surface diffusion [Fig. 1(a)]. The grooved surface topography, characteristic for the growth at the reduced temperature of $1000^{\circ} \mathrm{C}$, pertains to seize oxygen incorporation particularly if facets along (1010) and (1011) planes are exposed to the growth environment. These planes are known for their potential for preferential oxygen absorption. ${ }^{19,20}$ The process temperature is set to $1100^{\circ} \mathrm{C}$ for the rest of the growth runs considered in this paper following the development of a smooth surface topography, and consequently less oxygen incorporation.
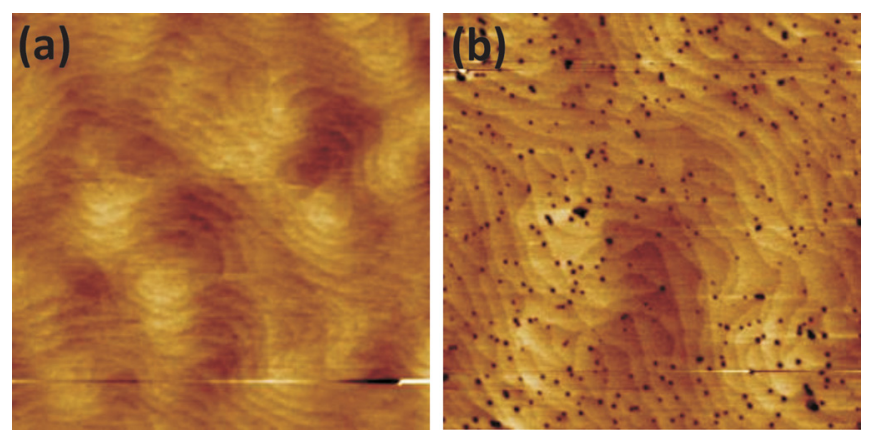

FIG. 1. AFM images representing the surface topography of high-Alcontent $\mathrm{Al}_{0.77} \mathrm{Ga}_{0.23} \mathrm{~N}$ layers grown at the low growth rate of $\sim 360 \mathrm{~nm} / \mathrm{h}$, high process temperature of $1100{ }^{\circ} \mathrm{C}$ and: (a) $[\mathrm{Si}] \sim 3 \times 10^{18} \mathrm{~cm}^{-3}$; (b) [Si] $\sim 2 \times 10^{19} \mathrm{~cm}^{-3}$. Scan size of both images is $2 \times 2 \mu \mathrm{m}^{2}$. The $\mathrm{rms}$ value over the $2 \times 2 \mu \mathrm{m}^{2}$ scan is $0.30 \mathrm{~nm}$ and $0.25 \mathrm{~nm}$, respectively.
For the purposes of investigating the role of oxygen in the conductivity of the $\mathrm{Al}_{0.77} \mathrm{Ga}_{0.23} \mathrm{~N}$ :Si layers, and at a process temperature of $1100{ }^{\circ} \mathrm{C}$, a certain leak is allowed upstream from the deposition zone. The concentration of the incorporated oxygen is enhanced by about one order of magnitude, up to the moderate level of $[\mathrm{O}] \sim 2 \times 10^{18} \mathrm{~cm}^{-3}$. The immediate consequence of the intentional addition of water vapor to the gas stream is a certain decrease of the growth rate. It is inferred to result from the formation of non-volatile products (suggested as $\mathrm{Al}_{2} \mathrm{O}_{3}, \mathrm{Al}(\mathrm{OH})_{3}{ }^{7}$ ) depleting the gasphase from Al-containing species.

The focus, further on, is placed on the $\mathrm{Al}_{0.77} \mathrm{Ga}_{0.23} \mathrm{~N}: \mathrm{Si}$ layers, containing moderate oxygen concentration at the level of $[\mathrm{O}] \sim 2 \times 10^{18} \mathrm{~cm}^{-3}$. Basically, this oxygen concentration compares with the moderate silicon concentration introduced from the intentional $\mathrm{SiH}_{4}$ doping. In terms of the labels in Fig. 2, these are the layers L1 and L2. The label L2* stands for an $\mathrm{Al}_{0.77} \mathrm{Ga}_{0.23} \mathrm{~N}$ :Si layer grown under the conditions of no intentional leak reflected in its oxygen concentration of $[\mathrm{O}] \sim 3 \times 10^{17} \mathrm{~cm}^{-3}$. Any of the three layers$\mathrm{L} 1, \mathrm{~L} 2$, and L2*-yields resistivity of less than $0.05 \Omega \mathrm{cm}$, which is on par with the best up-to-date reported values. ${ }^{4}$ For all layers, the electron mobility is $\sim 80 \mathrm{~cm}^{2} \mathrm{~V}^{-1} \mathrm{~s}^{-1}$ in the range of carrier concentrations in the low $10^{18} \mathrm{~cm}^{-3}$. It is to be noted that good transport properties are achieved for a moderate concentration level of $[\mathrm{O}] \sim 2 \times 10^{18} \mathrm{~cm}^{-3}$. The $\mathrm{Si}$ concentration is in the range of $[\mathrm{Si}] \sim(2-3) \times 10^{18} \mathrm{~cm}^{-3}$.

As the $\mathrm{Si}$ concentration in the layers increases, their transport properties deteriorate alongside with the surface morphology deterioration. This is evident by the appearance of pits in the respective AFM images. Pits start to form at [Si] $\sim 2 \times 10^{19} \mathrm{~cm}^{-3}$ as shown in Fig. 1(b). This AFM image corresponds to the surface topography of the layer L3 in terms of the labels in Fig. 2. Figure 2 represents the Si incorporation for two sets of layers as a function of the gas-flowrate ratio $\mathrm{SiH}_{4} /(\mathrm{TMAl}+\mathrm{TMGa})$. The set of layers $\mathrm{L} 1-\mathrm{L} 4$ is grown at $\sim 360 \mathrm{~nm} / \mathrm{h}$. The set of layers T1-T4 is grown at $\sim 760 \mathrm{~nm} / \mathrm{h}$. The about twofold increase of the growth rate is established by the twofold increase of the total (TMAl + TMGa) gas-flow rate while keeping the same Al composition in the gas-phase. Under the conditions of twofold increase of the growth rate, pit-populated morphology develops already at $[\mathrm{Si}] \sim 7 \times 10^{18} \mathrm{~cm}^{-3}$ (layer T1 in terms

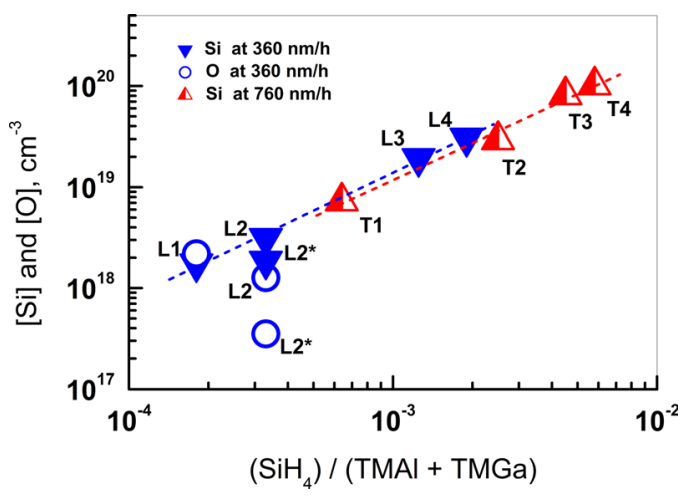

FIG. 2. Plots of silicon incorporation in two sets of high-Al-content $\mathrm{Al}_{\mathrm{x}} \mathrm{Ga}_{1-\mathrm{x}} \mathrm{N} \quad(\mathrm{x} \sim 0.77)$ layers. The set of layers L1-to-L4 is grown at $\sim 360 \mathrm{~nm} / \mathrm{h}$. The set of layers T1-to-T4 is grown at $\sim 760 \mathrm{~nm} / \mathrm{h}$. The concentration of the incorporated $\mathrm{O}$ is indicated for the layers L1, L2, and L2*. 
of the labels in Fig. 2). Figure 2 indicates that, for any growth rate, the $\mathrm{Si}$ atoms incorporation in the studied layers is inversely proportional to the input (TMAl + TMGa) gasflow-rate. For all that, when the doping is performed at low growth rate, the same $\mathrm{Si}$ doping level in the $\mathrm{Al}_{0.77} \mathrm{Ga}_{0.23} \mathrm{~N}$ alloy can be obtained for a reduced flow of $\mathrm{SiH}_{4}$ given that $\mathrm{Si}$ atoms substitute for atoms in the (Al, Ga) sub-lattice. This has the important consequence of obtaining high-Al-content $\mathrm{Al}_{0.77} \mathrm{Ga}_{0.23} \mathrm{~N}$ doped layers of pit-free surface morphology and retained transport properties.

Admittedly, ${ }^{21}$ the formation of pits-caused by the raised $\mathrm{Si}$ doping level especially under the conditions of enhanced growth rate-entails high resistivity. The layer T4 in Fig. 2, grown at $\sim 760 \mathrm{~nm} / \mathrm{h}$ and heavily doped to [Si] $\sim 1 \times 10^{20} \mathrm{~cm}^{-3}$, represents an extreme case. The relaxation of the Si-doping-induced tensile $\operatorname{strain}^{22}$ creates cracks as evident from its panchromatic CL image [Fig. 3]. The purpose here is, however, to point to the observed pits of bright contrast. These pits are reminiscent of the pits discussed in relation to the kinetic effects during AIN epitaxial growth and associated with nanopipes/large pinholes. ${ }^{14}$ High growth rate and/or heavy Si doping can stir surface roughness, giving rise to crystallographically faceted pits. ${ }^{20}$ The surface mobility of oxygen and silicon atoms present during growth is driven towards preferential absorption and accumulation at pits containing facets along particular planes such as (1010) and (1011). ${ }^{20,23}$ As a result, most probably, the density of active dopants decreases. ${ }^{23}$

Some incorporation of $\mathrm{Si}$ and $\mathrm{O}$ atoms as substitutional defects in the crystal lattice must occur. Their fraction, though, is seemingly not enough as to give rise to any signal in the respective EPR spectra taken from any of the layers with pit-populated morphology (Fig. 4, the EPR spectrum corresponding to the layer T1 in the labels of Fig. 2). Besides the layers with typical thickness of $\sim 360 \mathrm{~nm}$ included in this study, the investigation has also been concerned with layers

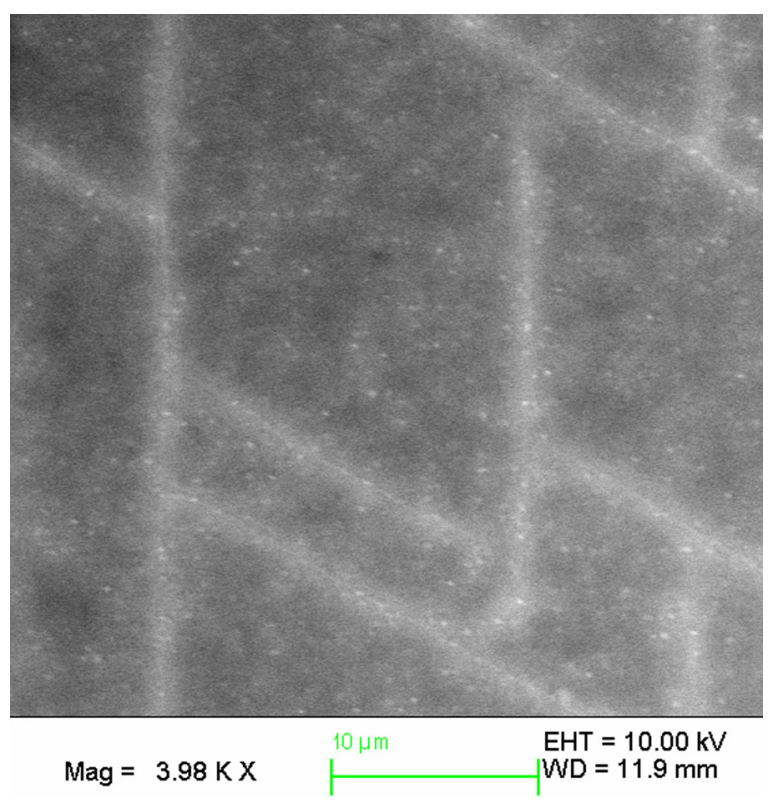

FIG. 3. Pits of bright contrast and cracks on the panchromatic CL image of high-Al-content $\mathrm{Al}_{\mathrm{x}} \mathrm{Ga}_{1-\mathrm{x}} \mathrm{N}$ layer heavily doped to $[\mathrm{Si}] \sim 1 \times 10^{20} \mathrm{~cm}^{-3}$ (the layer T4 in terms of the labels in Fig. 2). The bar scale corresponds to $10 \mu \mathrm{m}$.

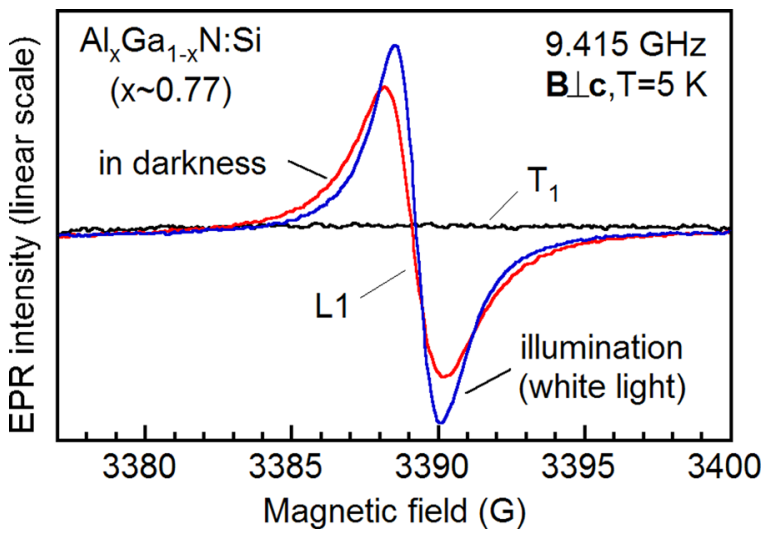

FIG. 4. EPR spectra measured at $5 \mathrm{~K}$ for $\mathrm{B} \| \mathrm{c}$ in darkness and under illumination with white light in $\mathrm{Al}_{0.77} \mathrm{Ga}_{0.23} \mathrm{~N}$ :Si layers characterized by: (i) smooth and pit-free morphology, and comparable $\mathrm{Si}$ and $\mathrm{O}$ atomic concentrations of $\sim 2 \times 10^{18} \mathrm{~cm}^{-3}$ (the layer L1 in terms of the labels in Fig. 2); and (ii) pitpopulated morphology (the layer T1 in terms of the labels in Fig. 2).

of substantial thickness, $\sim 2 \mu \mathrm{m}$, as to increase the volume of the probed material and improve the collected signal/noise ratio in the EPR spectra. Furthermore, such thick layers contained oxygen at the level of $[\mathrm{O}] \sim 4 \times 10^{17} \mathrm{~cm}^{-3}$ being two orders of magnitude less than the incorporated Si to minimize the effect of any potential O-related compensation.

Notably, EPR spectra in darkness at $5 \mathrm{~K}$ are recorded from the $\mathrm{Al}_{0.77} \mathrm{Ga}_{0.23} \mathrm{~N}$ :Si layers with thickness of $\sim 360 \mathrm{~nm}$ characterized by a smooth and pit-free surface morphology resulting from applying low grow rate and moderate doping of $[\mathrm{Si}] \sim(2-3) \times 10^{18} \mathrm{~cm}^{-3}$ (Fig. 4, the EPR spectrum corresponding to the layer L1 in the labels of Fig. 2). As already pointed out, these layers yield resistivity of less than $0.05 \Omega$ $\mathrm{cm}$ for electron mobility of $80 \mathrm{~cm}^{2} \mathrm{~V}^{-1} \mathrm{~s}^{-1}$ at carrier concentration of low $10^{18} \mathrm{~cm}^{-3}$. Illumination with white light induces relative changes in the line shape and the g-value but not the total intensity of the EPR spectrum. The relative changes of the EPR spectrum are attributed mainly to the presence of two donors, $\mathrm{Si}$ and $\mathrm{O}$, and their overlapping contribution to the total signal. In darkness, and at low temperature, the population of carriers is higher on the apparently deeper $\mathrm{O}$ level. This gives rise to a relatively broader line with a $\mathrm{g}$-value of $\mathrm{g}=1.9848 \pm 0.0001$ due to a larger contribution of $\mathrm{O}$ to the total EPR signal. A broad signal may be expected from the substitutional $\mathrm{O}_{\mathrm{N}}$ donor following the discussion in Ref. 11, and based on arguments about the hyperfine interactions between the unpaired electron spin and the nuclear spins of nearest neighbors in the $\mathrm{Al}(\mathrm{Ga})$ sub-lattice. Under illumination, carriers redistribute with increasing the population on the Si level giving rise to a narrower line width expected for the Si shallow donor. ${ }^{11}$ The insensitivity of the EPR intensity on illumination indicates that carrier compensation by traps in the upper part of the band gap, including traps associated with oxygen, is negligible. This is to be particularly noted as the oxygen concentration in these $\mathrm{Al}_{0.77} \mathrm{Ga}_{0.23} \mathrm{~N}$ :Si layers increases by one order of magnitude from $[\mathrm{O}] \sim 3 \times 10^{17} \mathrm{~cm}^{-3}$ in the layer L2* to [O] $\sim 2 \times 10^{18} \mathrm{~cm}^{-3}$ in the layer L1 [Fig. 2]. The findings of the EPR study suggest that silicon and oxygen behave as shallow donors in the high-Al-content layers of $\mathrm{Al}_{0.77} \mathrm{Ga}_{0.23} \mathrm{~N}$ alloy composition. 


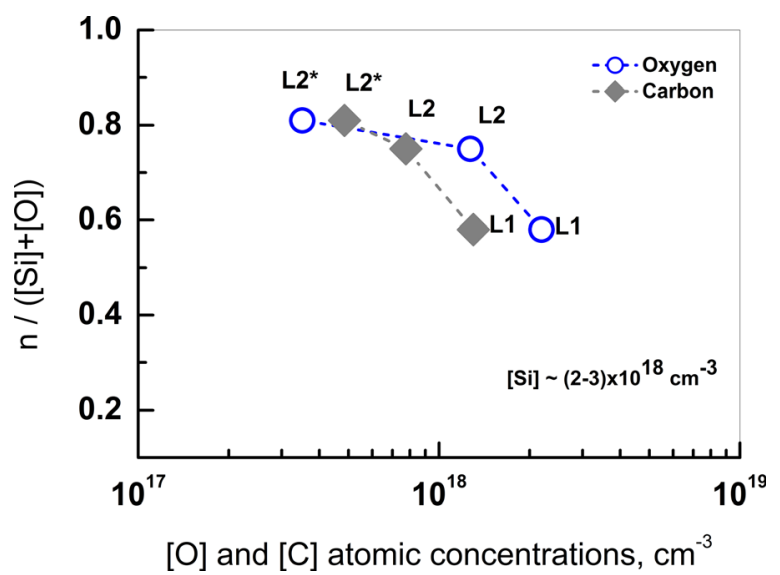

FIG. 5. Ratio of carrier concentration (n) to the total concentration of incorporated $\mathrm{Si}$ and $\mathrm{O}$ atoms, $\mathrm{n} /([\mathrm{Si}]+[\mathrm{O}])$, vs. the increase of atomic concentration of major impurities $\mathrm{O}$ and $\mathrm{C}$ as measured by SIMS.

Acknowledging that both $\mathrm{Si}$ and $\mathrm{O}$ may potentially contribute carriers for the n-type conductivity of the $\mathrm{Al}_{0.77} \mathrm{Ga}_{0.23} \mathrm{~N}$ :Si layers studied here, we further consider the ratio of carrier concentration (n) to the total concentration of incorporated $\mathrm{Si}$ and $\mathrm{O}$ atoms. A rather high ratio of $\mathrm{n} /([\mathrm{Si}]+[\mathrm{O}]) \sim 0.80$ is generally determined, particularly for [Si] dominating [O] within a factor of about 10 (Fig. 5, the layer $\mathrm{L} 2 *)$. In the $\mathrm{Al}_{0.77} \mathrm{Ga}_{0.23} \mathrm{~N}$ :Si layers with intentional doping level of $[\mathrm{Si}] \sim(2-3) \times 10^{18} \mathrm{~cm}^{-3}$ studied here, the concentration of major impurities $\mathrm{O}$ and $\mathrm{C}$ changes independently on the Si concentration but in apparent correlation with each other [Fig. 5]. As both, the $\mathrm{O}$ and $\mathrm{C}$ atomic concentration increases to become comparable to that of the $\mathrm{Si}$ atomic concentration, the ratio of $\mathrm{n} /([\mathrm{Si}]+[\mathrm{O}])$ ascribed to the layer $\mathrm{L} 1$, respectively, drops to $\sim 0.55$. This layer still retains the transport properties of its partner layers L2* and L2 in terms of carrier concentration of $\mathrm{n} \sim 2 \times 10^{18} \mathrm{~cm}^{-3}$. However, a certain level of carrier compensation is apparent as the total concentration of the incorporated $\mathrm{Si}$ and $\mathrm{O}$ atoms in the layer $\mathrm{L} 1$ is $([\mathrm{Si}]+[\mathrm{O}]) \sim 4 \times 10^{18} \mathrm{~cm}^{-3}$. The carrier compensation plausibly involves $\mathrm{C}$ as well as $\mathrm{O}$ impurities, especially considering their interrelated incorporation into the studied $\mathrm{Al}_{0.77} \mathrm{Ga}_{0.23} \mathrm{~N}$ :Si layers. Obviously, the implemented growth conditions have resulted in a certain balance of the incorporated intrinsic and substitutional point defects. The potential of substitutional $\mathrm{O}_{\mathrm{N}}$ to contribute free carriers must be precluded by its involvement in the formation of defect complexes likely located in the lower half of the band gap.

In conclusion, the dopant and impurity incorporation kinetics, as established by applying a high process temperature together with a low growth rate, is implicit in the control of n-type high-Al-content $\mathrm{Al}_{0.77} \mathrm{Ga}_{0.23} \mathrm{~N}$ :Si layers. The criterion for high enough process temperature and low enough growth rate is the development of a smooth surface topography preventing faceting, which can cause pits formation indicated to be detrimental for the transport properties of the layers. Following the kinetics of the Si incorporation, which is inversely proportional to the input metal-organic gas-flowrate, a low growth rate benefits the implementation of a reduced $\mathrm{SiH}_{4}$ flow to retain a pit-free morphology yet achieving the relevant $\mathrm{Si}$ incorporation for efficient carrier concentration. The EPR study was only possible on $\mathrm{Al}_{0.77} \mathrm{Ga}_{0.23} \mathrm{~N}$ :Si layers of pit-free morphology. The EPR study suggests $\mathrm{Si}$ and $\mathrm{O}$ to behave as shallow donors. Carrier compensation by traps in the upper part of the band gap, including traps associated with oxygen, is negligible, even in the layers with comparable concentration of $\mathrm{Si}$ and $\mathrm{O}$ in the range of low $10^{18} \mathrm{~cm}^{-3}$. Certain mechanism of carrier compensation by traps in the lower part of the band gap, however, is given rise at these moderate $\mathrm{O}$ concentrations (indicated by the drop in the ratio $\mathrm{n} /(\mathrm{Si}+\mathrm{O})$ ). It appears relevant to be put in the context of the observed interrelated incorporation of the other major impurity established in the layers, namely, carbon.

Support from the Swedish Research Council (VR), the Linköping Linnaeus Initiative for Novel Functionalized Materials (VR), and the Swedish Energy Agency is gratefully acknowledged. A.K.G. acknowledges support from the Swedish Governmental Agency for Innovation Systems (VINNOVA).

${ }^{1}$ Y. Taniyasu, M. Kasu, and N. Kobayashi, Appl. Phys. Lett. 81, 1255 (2002).

${ }^{2}$ M. Pophristic, S. P. Guo, and B. Peres, Appl. Phys. Lett. 82, 4289 (2003).

${ }^{3}$ M. L. Nakarmi, K. H. Kim, K. Zhu, J. Y. Lin, and H. X. Jiang, Appl. Phys. Lett. 85, 3769 (2004).

${ }^{4}$ R. Collazo, S. Mita, J. Xie, A. Rice, J. Tweedie, R. Dalmau, and Z. Sitar, Phys. Status Solidi C 8, 2031 (2011).

${ }^{5}$ S. Keller, P. Cantu, C. Moe, Y. Wu, S. Keller, U. K. Mishra, J. S. Speck, and S. P. DenBaars, Jpn. J. Appl. Phys. Part 1 44, 7227 (2005).

${ }^{6}$ T. F. Kuech, E. Veuhoff, and B. S. Meyerson, J. Cryst. Growth 68, 48 (1984).

${ }^{7}$ T. F. Kuech, D. J. Wolford, E. Veuhoff, V. Deline, P. M. Mooney, R. Potemski, and J. Bradley, J. Appl. Phys. 62, 632 (1987).

${ }^{8}$ T. Mattila and R. M. Nieminen, Phys. Rev. B 54, 16676 (1996).

${ }^{9}$ L. Silvestri, K. Dunn, S. Prawer, and F. Ladouceur, Appl. Phys. Lett. 99, 122109 (2011).

${ }^{10}$ R. Zeisel, M. W. Bayerl, S. T. B. Goennenwein, R. Dimitrov, O. Ambacher, M. S. Brandt, and M. Stutzmann, Phys. Rev. B 61, R16283 (2000).

${ }^{11}$ N. T. Son, M. Bickermann, and E. Janzén, Appl. Phys. Lett. 98, 092104 (2011).

${ }^{12}$ A. Kakanakova-Georgieva, R. R. Ciechonski, U. Forsberg, A. Lundskog, and E. Janzén, Cryst. Growth Des. 9, 880 (2009).

${ }^{13}$ A. Kakanakova-Georgieva, G. K. Gueorguiev, S. Stafström, L. Hultman, and E. Janzén, Chem. Phys. Lett. 431, 346 (2006).

${ }^{14}$ A. Kakanakova-Georgieva, D. Nilsson, and E. Janzén, J. Cryst. Growth 338, 52 (2012).

${ }^{15}$ A. Kakanakova-Georgieva, D. Nilsson, M. Stattin, U. Forsberg, ̊. Haglund, A. Larsson, and E. Janzén, Phys. Status Solidi (RRL) 4, 311 (2010).

${ }^{16}$ Evans Analytical Group (EAG): e.g., P. K. Chu, et al., J. Vac. Sci. Technol. B 16, 197 (1998).

${ }^{17}$ D. Nguyen, K. Hogan, A. Blew, and M. Cordes, J. Cryst. Growth 272, 59 (2004).

${ }^{18}$ K. Balakrishnan, A. Bandoh, M. Iwaya, S. Kamiyama, H. Amano, and I. Akasaki, Jpn. J. Appl. Phys. Part 2 46, L307 (2007).

${ }^{19}$ J. Elsner, R. Jones, M. Haugk, R. Gutierrez, Th. Frauenheim, M. I. Heggie, S. Öberg, and P. R. Briddon, Appl. Phys. Lett. 73, 3530 (1998).

${ }^{20}$ Z. Liliental-Weber, Y. Chen, S. Ruvimov, and J. Washburn, Phys. Rev. Lett. 79, 2835 (1997).

${ }^{21}$ B. S. Simpkins, E. T. Yu, U. Chowdhury, M. M. Wong, T. G. Zhu, D. W. Yoo, and R. D. Dupuis, J. Appl. Phys. 95, 6225 (2004).

${ }^{22}$ I. C. Manning, X. Weng, J. D. Accord, M. A. Fanton, D. W. Snyder, and J. M. Redwing, J. Appl. Phys. 106, 023506 (2009).

${ }^{23}$ M. E. Hawkridge and D. Cherns, Appl. Phys. Lett. 87, 221903 (2005). 